We try to publish authors' responses in the same edition with readers' comments. Time constraints might prevent this in some cases. The problem is compounded in a bimonthly journal where continuity of comment and redress are difficult to achieve. When the redress appears 2 months after the comment, 4 months will have passed since the article was published. Therefore, we would suggest to our readers that their correspondence about published papers be submitted as soon as possible after the article appears.

\section{Irritant-Induced Anosmia}

To the Editor: The article by Prudhomme et al $^{1}$ in the January-February issue of the $7 A B F P$ pointed out the paucity of reports of objectively measured olfactory impairment after exposure to ammonia. Having treated a 44-year-old man who had acute overexposure to anhydrous ammonia with acute upper respiratory tract burns and who complained persistently of a perceived loss of sense of taste, I read this article with particular interest. In trying to arrange for objective testing of my patient's olfactory function, I discovered that administration of the University of Pennsylvania Smell Identification Test (UPSIT) or any other quantitative olfactory function test is not a commonly performed procedure in my geographic area. Even the otolaryngology departments of the nearby universities did not use this test.

Because I needed to rate my patient's permanent partial impairment, I chose to obtain the UPSIT and administer the test myself. I found it very simple to administer, and the documentation and instructions that came with the kit were straightforward and useful. The results of my patient's test were consistent with anosmia, which I believe, within a reasonable degree of medical certainty, was caused by acute exposure to anhydrous ammonia.

Allen R. Edwards, MD Charlotte, NC

\section{Reference}

1. Prudhomme JC, Shusterman DJ, Blanc PD. Acute-onset persistent olfactory deficit resulting from multiple overexposures to ammonia vapor at work. J Am Board Fam Pract 1998;11:66-9.

The above letter was referred to an author of the article in question, who offers the following reply.

To the Editor: Dr Edwards' experience is consistent with our impression that irritant-induced anosmia subsequent to high-level exposure is more frequent than generally appreciated. That both Dr. Edwards' and our cases occurred after ammonia inhalation might reflect the widespread use of this particular irritant (especially as a commercial refrigerant), although the physical properties of the chemical, especially its water solubility, might also come into play.

A recent case report of chlorine-induced anosmia, 1 however, underscores that anosmia is an adverse outcome that might be attributable to a number of different chemicals. Dr. Edwards' extra efforts to quantify his patient's impairment are to be commended. This effort is often all the more so important in occupationally related illness, an area of particular relevance in general and family practice. ${ }^{2}$

Paul Blanc, MD, MSPH University of California San Francisco

\section{References}

1. Banjamin E, Pickles J. Chlorine-induced anosmia. A case presentation. J Laryng Otol 1997;111;1075-6.

2. Goodwin P, Wall EM, Bajorek M. Occupational medicine content of Oregon family physician practices. J Am Board Fam Pract 1995;8:300-4. 